Railway Engineering

Jan 2021

Issue:13, Page: 14-28

Review Article

doi: 10.47072/demiryolu.787758

http://dergipark.org.tr/demiryolu

e-ISSN: 2687-2463, ISSN: 2149-1607

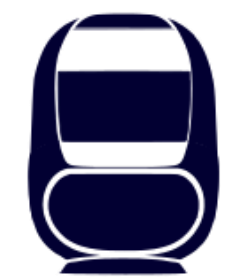

\title{
Ray Pedi ve Travers Altı Pedlerin Hat Bileşenleri ve Hat Performansı Üzerindeki Etkileri
}

\author{
Erdem BALCI®
}

\author{
Istanbul Üniversitesi-Cerrahpaşa, Mühendislik Fakültesi, İnşaat Mühendisliği Bölümü, \\ İstanbul, Türkiye \\ erdembalci@outlook.com
}

(Alınıs/Received: 29.08.2020, Kabul/Accepted: 10.10.2020, Yayımlama/Published: 31.01.2021)

\begin{abstract}
Öz: Bir demiryolu hattının esneme direnci hat performansını önemli ölçüde etkiler. İstenilen esneme direncini hat üzerinde sağlayabilmek için ray pedleri ve travers altı pedlere ihtiyaç duyulur. Ray pedleri, ray ondülasyonlarının engellenmesini ve traverslerin dinamik yük tahribatlarına karşı korunmasını sağlar. Travers altı pedler ise balast tabakasındaki aşınmayı azaltır. Yumuşak ped kullanımı hatta daha eşit bir yük dağılımı sağlarken bir diğer yandan da hat sehimlerini artırır. Bu nedenle, kullanılan pedlerin, maksimum hat performansını sağlayacak şekilde optimum esneme direncine sahip olması gerekir. Bu çalışmada, ray pedleri ve travers altı pedleri kullanımının ray, travers ve balast katmanı üzerindeki etkileri araştırılmışıır. Böylece pedlerin, hat tasarımında göz önünde bulundurulması gereken hususlar üzerindeki etkilerini içeren temel bir kaynak oluşturmak hedeflenmiştir. Çalışma sonucunda elastik pedlerin esneme direncinin, her bir hat katmanı üzerinde gerilme, moment, titreşim ve yer değiştirme kriterleri açısından farklı etkileri olduğu görülmüştür. Yeni inşa edilen veya yenileme çalışması yapılan bir hatta maksimum hat performansının sağlanabilmesi için önerilere yer verilmiştir.
\end{abstract}

Anahtar kelimeler: Ray Pedi, Travers Altı Ped, Hat Performansı, Hat Esneme Direnci, Hat Bileşenleri

\section{The effects of the Rail Pads and Under Sleeper Pads on the Track Components and Track Performance}

\begin{abstract}
Railway track stiffness is a highly effective parameter of track performance. In order to provide desired track stiffness, rail pads and under sleeper pads can be used. These two pads have different impacts on different track layers. Rail pads restrain the improvement of rail corrugations and preserve the sleeper against the dynamic impact loads. Under sleeper pads reduce the attrition of the ballast layer. While soft pads allow even distribution of wheel loads, they also lead to high track deflections. Therefore, pads must have optimum stiffness value that will provide maximum track performance. In this work, the effect of the use of rail pads and under sleeper pads on the rail, sleeper, and ballast layer are investigated. Thereby, it is aimed to create a fundamental resource that covers the effects of pads on the subjects that must be considered in railway track design. As a result, it is observed that the stiffness of the rail pads has different effects in terms of stress, moment, vibration, and movement criteria. Suggestions for providing maximum track performance in a newly constructed track or a track with replacement work are offered.
\end{abstract}

Keywords: Rail Pad, Under Sleeper Pad, Track Performance, Track Stiffness, Track Components

\section{Giriş}

Demiryolları, günümüzde uzun mesafe taşımacılığında kullanılabilen güvenli ve ekonomik bir ulaştırma aracıdır. Diğer ulaştırma türlerine kıyasla birçok avantajının bulunmasının yanı sıra, dünya çapındaki aktif araştırmalara konu olan önemli problemler de mevcuttur. Ray yüzey kusurları, tanecikli katmanlardaki oturmalar, malzemelerin yorulması gibi hat geometrik kalite bozuklukları hattın dayanıklılığını azaltır. Hava ile yayılan gürültü ve titreşim dalgalarının zeminden yayılımı, sosyal ve çevresel problemlere yol açabilir [1].

Atıf için/Cite as: E. Balcı, "Ray pedi ve travers altı pedlerin hat bileşenleri ve hat performansı üzerindeki etkileri," Demiryolu Mühendisliği, no. 13, pp. 14-28, Jan. 2021. doi: 10.47072/demiryolu.787758 
Birçok farklı hat geometrik bozulma çeşidi vardır [2, 3]. Ray, travers ve ray bağlantı elemanları, hat performansı üzerinde önemli bir rol oynadığından bu elemanlardaki yıpranmalar, yüksek bakım maliyetlerinin yanı sıra güvenliği tehdit eden boyutlara ulaşabilir. Ancak bu bileşenler, yapıldıkları malzemeden dolayı yüksek yorulma dayanımına ve dayanıklılığa sahiptir [1]. Bu nedenle, servis ömürlerini doldurduklarında en iyi çözüm onları değiştirmektir [4]. Bir diğer hat bozulma nedeni de tanecikli katmanlarda tekrarlı tren yükleri altında giderek artan sehimlerdir. Hat sehimlerinin artması, yolcu konforunu azaltır ve ilerleyen boyutlarında işletme güvenliğini tehdit eden bir unsurdur. Taneciklerdeki kırılmalar ve tanecikler arasındaki temas kaybı, hat katmanında oturmaya neden olur. Selig ve Water (1994), ortalama tabaka oturması ile hat düşey sehimleri arasında doğrusal bir ilişki olduğu gözlemledi [5]. Bir diğer deyişle, balast ve alt balast tabakasındaki yıpranmalar, hat geometrik kalitesini düşürerek hattın performansını azaltır.

Bir diğer önemli işletim problemi, hatta oluşan titreşim ve bunun sonucunda ortaya çıkan gürültüdür. Trenden aktarılan dinamik yükler ile hattın tahriki sonucunda titreşim hareketleri meydana gelir. Zemin ile aktarılan yapısal titreşimler hat bozulmalarına neden olur. Ray ondülasyonları, ray mantarının üst yüzeyinde meydana gelen ve hattan tren geçişi esnasında dinamik zorlanmaya yol açan dalgalı aşınmalardır. Ray şeklinin bozulması veya raydaki üretim hataları uzun dalga ondülasyonuna neden olurken balast oturmaları, hat boyunca esneme direnci değişimi, teker düzlükleri, makaslar, ray bağlantıları gibi unsurlar da kısa dalga ondülasyonuna yol açar. Hattı dinamik olarak zorlayan ray ondülasyonları önemli bir titreşim kaynağıdır. Yükleme frekansları ile hattın doğal frekansları eşit olduğunda "rezonans" durumu meydana gelir. Bu durum, hat bileşenlerinin yorulmasına ve bazen balast sıvılaşmasına neden olarak hat servis ömrünün kısalmasına, hat stabilitesinin ve yolcu konforunun azalmasına yol açar [6]. Yapısal hat gürültüsü ise mekanik titreşimlerin yayılmasıyla ortaya çıkan yüksek frekanslı dalgalardır. Yolcu konforunu azaltan ve hat çevresinde oturanlara rahatsızlık veren bir unsurdur.

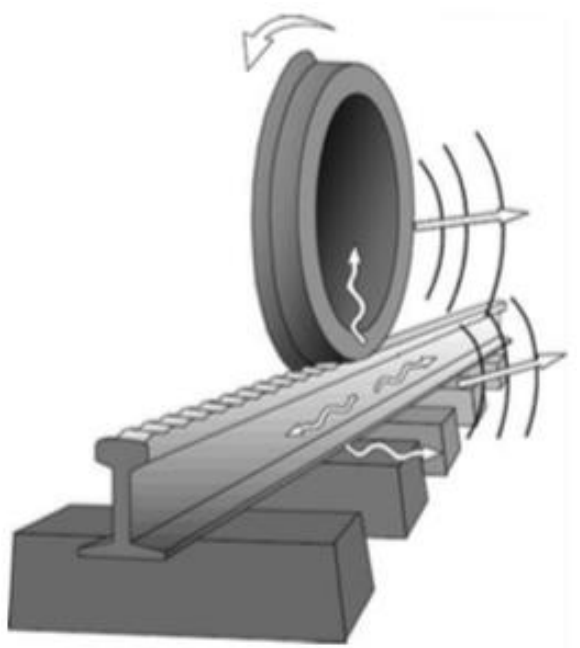

Şekil 1. Tekerin kusurlu ray yüzeyinde gidişatı sırasında oluşan gürültü [7]

Yukarıda verilen problemlerin çeşitli çözüm yolları vardır. Örneğin balast tabakasındaki oturmalar; daha iyi malzeme kullanımı, bakım sıklı̆̆ının artırılması veya bu tabakanın yenilenmesiyle çözülebilir [1]. Bunun yanı sıra balast tabakasındaki gerilmeler daha eşit şekilde dağıtılabilir. Hat titreşimleri ve gürültü ise hat esneme direncinden büyük oranda etkilenir. Elastik pedler yardımıyla hat esneme direnci istenilen değerde tutularak titreşimler ve gürültü kontrol altına alınılabilir. Elastik pedler, hattaki esneme direnci farklılıklarını azaltarak daha stabil bir tren geçişi sağlar. Bu nedenle, elastik elemanlar demiryolu inşaatının önemli bir parçasıdır.

Bu çalışma, elastik pedlerin, çeşitli hat katmanları üzerindeki etkisini kapsamaktadır. Ray pedi ve travers altı pedlerin ray, travers ve balast katmanı üzerindeki etkilerini kapsayan bir literatür 
araştırması yapılmıştır. Elastik eleman kullanımının hat tasarımında sağladığı yararlar ve farklı esneme direncine sahip pedlerin hat üzerindeki etkilerini kapsayan deneysel çalışmalara yer verilmiştir. Böylece ray pedlerinin ve travers altı pedlerin önemini ortaya koyan temel bir kaynak oluşturmak hedeflenmiştir.

\section{Elastik Pedlerin Hat Üzerindeki Etkileri}

\subsection{Ray pedleri ve hat üzerindeki etkileri}

Ray pedi, teker/ray etkileşiminden gelen yüklerin yapı üzerindeki tahribatını azaltmak amacıyla ray tabanı ila travers arasına yerleştirilir. Metro ve bazı diğer ulaştırma sistemlerinde raylar doğrudan hatta tespitlenir. Bu durumda teker/ray etkileşiminden doğan titreşimler ray pedi ile sönümlenmeye çalışıldığı için ray pedi sistemin oldukça önemli bir parçasıdır. Ray pedi esneme direncindeki değişimler balastsız hattın mekanik tepkileri üzerinde önemli bir rol oynar [8]. Şekil 2(a)'da ray pedinin, W21 ray bağlantı sistemi içerinde kullanımı ve Şekil 2(b)'de kauçuk bir ray pedi örneği gösterilmiştir.

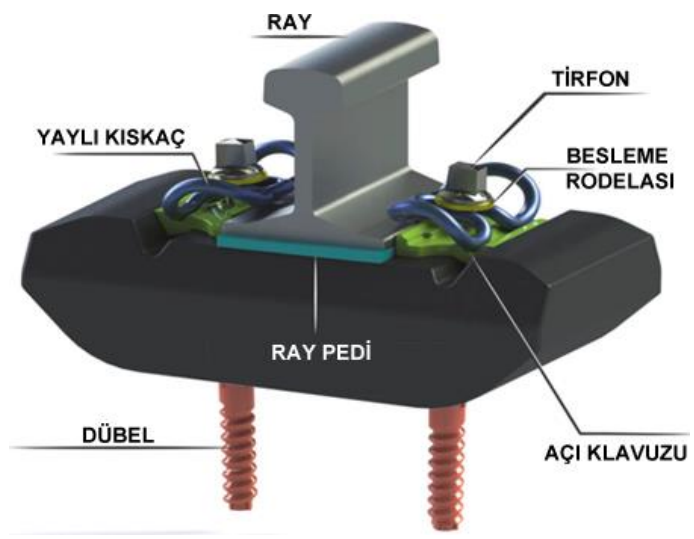

a)

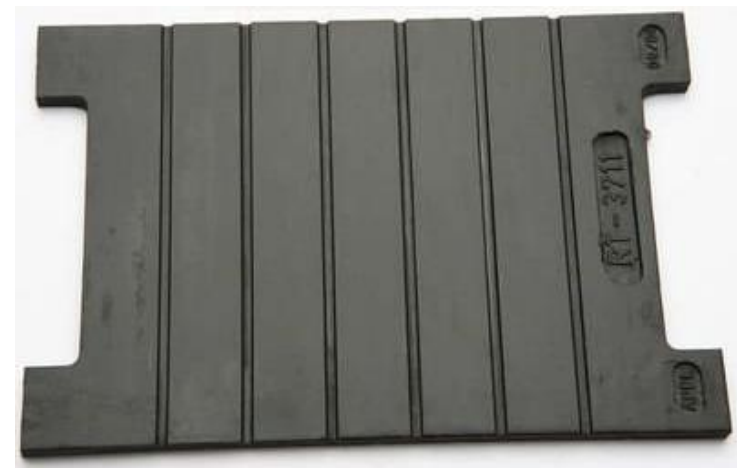

b)

Şekil 2. a) W21 ray bağlantı sistemi elemanları [9] b) Kauçuk, oluklu bir ray pedi [10]

Ray pedinin esneme direnci pedin karakteristik bir özelliği olup ray pedlerini sınıflandırmada kullanılan ana parametredir. Ancak farklı hat uygulamalarında, hattın karakteristik yapısına bağlı olarak pedlerin sınıflandırılması da değişiklik göstermiştir. Tablo 1'de farklı çalışmalarda ve bir yönetmelikte ray pedi sınıflandırması için önerilen esneme direnci değerleri görülmektedir. Tabloda ray pedinin esneme direnci $\mathrm{k}$, hattın esneme direnci ise $\mathrm{K}$ ile temsil edilmiştir.

Tablo 1. Ray pedlerinin esneme direncine göre sınıflandırılması

\begin{tabular}{cccccc}
\hline \multirow{2}{*}{ Öneren } & \multicolumn{4}{c}{ Ray pedi esneme direncine $(\mathrm{kN} / \mathrm{mm})$ göre sinıflandırma } \\
\cline { 2 - 5 } & Çok Yumuşak & Yumuşak & Orta & Sert & Çok Sert \\
\hline EN 13481-1 [11] & $<100$ & $100<\mathrm{k}<200$ & $>200$ & \\
López-Pita [12] & $<80$ & $80<\mathrm{k}<150$ & $>150$ & \\
Gomes Correia ve & $\sim 130$ & $\sim 410$ & $\sim 1300$ & $\sim 4100$ \\
Cunha [13] & $2,23 \mathrm{~K}<\mathrm{k}<2,50 \mathrm{~K}$ & $2,50-3 \mathrm{~K}<\mathrm{k}<3-4 \mathrm{~K}$ & $3-4 \mathrm{~K}<\mathrm{k}<4-5 \mathrm{~K}$ & $4-5 \mathrm{~K}<\mathrm{k}<5 \mathrm{~K}$ & $>5 \mathrm{~K}$ \\
Hasan [14] & & &
\end{tabular}

Ray pedleri $4.5 \mathrm{~mm}$ ile $15 \mathrm{~mm}$ arasında değişen kalınlıklara sahiptir. Ray pedi kalınlığı, pedin esneme direnci ve mekanik performansı üzerinde önemli bir etkiye sahiptir. Farkl1 hatlara uyum sağlaması için farklı kalınlıklar kullanılır. Sol-Sánchez ve diğerleri (2014), ray pedi kalınlığının etkisini araştırdıkları çalışmada kalın pedlerin, daha iyi esnek gerinim toparlanmasına (elastic recovery), daha yüksek sehimlere ve daha yüksek enerji dağıtımına neden olduğunu ortaya 
koymuşlardır [15]. Kalınlığın artmasıyla, hattın alt katmanlarına iletilen kuvvet ve titreşimler azalır. Ancak ray pedi kalınlığı arttıkça, ray pedinin esneme direnci azalır ve yüksek ray sehimi meydana gelebilir. UIC 54 ray tipi altındaki pedler genellikle $180 \mathrm{~mm}$ uzunluk ve $140 \mathrm{~mm}$ genişlikte, UIC 60 ray tipi altındakiler ise $180 \mathrm{~mm}$ uzunluk ve $148 \mathrm{~mm}$ genişliktedir.

Ray pedleri, ped bağlantı elemanlarıyla birlikte burkulmaya karşı dirençli olmalı ve tekrarlı yükler altında bu direncini kaybetmemelidir. Sinyalizasyon ve kontrol amaçlı hat devresinden geçen akımı traverse aktarmayan bir yalıtım sağlamalıdır. Su, kimyasal maddeler, yağ ve toz nedeniyle zaman içerisinde kirlendiğinde esneklik özelliğini kaybetmemelidir ve iklim koşullarından etkilenmemelidir. Ray pedlerinin ideal servis ömrü, rayların servis ömrü kadardır [4].

Ray pedi seçimi tüm bu kriterleri sağlayacak şekilde, ideal kalınlık ve optimum esneme direnci gözetilerek yapılmalıdır. Genel olarak düşük esneme dirençli ray pedi kullanımı önerilmektedir. Ancak hem yumuşak hem de sert ray pedlerinin bazı dezavantajları bulunmaktadır. Ray pedinin hat bileşenleri üzerindeki temel etkileri [16] şöyle sıralanmıştır:

- Ray ondülasyonlarının (rail corrugation) hızlı gelişimini engeller.

- Hat titreşimleri ve teker/ray temas kuvvetleri üzerindeki etkileriyle traverslerin korunmasını sağlar.

- Balast tabakasındaki titreşimleri azaltarak taneciklerin yıpranmasını geciktirir.

- Tüm bu etkilerin boyutu, ray pedinin esneme direnci ile ilgili olarak değişmektedir.

\subsection{Ray pedi esneme direncinin hat üzerindeki etkileri}

Ray pedi esneme direnci, hattın farklı bileşenleri üzerinde farklı etkilere sahip olan önemli bir değerdir. Fransız Demiryollar $9 \mathrm{~mm}$ kalınlığında $90 \mathrm{kN} / \mathrm{mm}$ esneme direncine sahip ray pedleri kullanırken [17], Alman Demiryolları'nda statik esneme direnci $50-70 \mathrm{kN} / \mathrm{mm}$ ve dinamik esneme direnci $50-130 \mathrm{kN} / \mathrm{mm}$ olan pedler tercih edilir. Dinamik teker kuvvetleri ve hatta oluşacak titreşimleri karşılamak amacıyla pedlerde hava kabarcıkları, oluklar veya boşluklar birakılır [4].

Yumuşak ve sert ray pedi kullanmanın kendine göre avantajları ve dezavantajları vardır. Ray pedi esneme direnci, her bir hat problemini güvenli sinırlar içerisinde tutacak ve maksimum hat performansını sağlayacak şekilde seçilmelidir. Tablo 2'de yumuşak ve sert ped kullanımının hat üzerindeki etkileri özetlenmiştir. Devamında ise ray pedi esneme direncinin hat performansını düşüren problemler üzerindeki etkileri ayrıntılı olarak incelenmiştir.

Tablo 2. Sert ve yumuşak ray pedi kullanımının karşılaştırılması [1]

\begin{tabular}{lcc}
\hline \multicolumn{1}{c}{ Uygulama } & Sert ped & Yumuşak ped \\
\hline Teker/ray temas kuvvetlerinin etkisinin azaltılması & & $\checkmark$ \\
Hat esneme direnci değişimlerinin azaltılması & & $\checkmark$ \\
Ray ondülasyon gelişiminin engellenmesi & $\checkmark$ & \\
Ray sehimlerinin azaltılması & $\checkmark$ & $\checkmark$ \\
Ray hareketlerinin engellenmesi & & \\
Alt katmanlara aktarılan gerilmelerin azaltılması & $\checkmark$ & $\checkmark$ \\
Hat titreşim ve gürültünün azaltılması & $\checkmark$ & $\checkmark$ \\
Travers ve balast titreşimlerinin azaltılması & & \\
Travers hasarlarının engellenmesi & & $\checkmark$ \\
\hline
\end{tabular}

Song ve diğerleri (2020), ray pedi esneme direncinin ray ondülasyonları nedeniyle oluşan dinamik 
teker/ray etkileşimi üzerindeki etkilerini içeren bir nümerik analiz çalışması yapmıştır. Hiensch ve diğerleri (2002), bu etkileşimi saha ölçümleri ve simülasyon yardımıyla incelemiştir. Sato ve diğerleri (2002), ray ondülasyonları üzerine yapılan çalışmaları içeren bir literatür araştırması yapmıştır. Knothe ve Ripke (1989), ray ondülasyonlarına etki eden faktörleri incelemiştir. Diana ve diğerleri (1998), metrolardaki kısa dalga boylu ondülasyonlar üzerine deneysel ve nümerik bir çalışma yapmıştır. Egana ve diğerleri (2006), ray pedi esneme direncinin ray ondülasyonları üzerindeki etkisini, Ilias (1999) ise ondülasyon gelişimine etkisini incelemiş̧tir. Giannakos (2010), bir hat üzerinde ray pedi yenilemesi yaparak hattaki gerilme ve gürültü yayılımındaki değişimleri kaydetmiştir. Kaewunruen ve Remennikov (2008), dinamik yükler altında ray pedlerinin traverslerin eğilme davranışı üzerindeki etkisini gözlemlemiştir. Carrascal ve diğerleri (2011), ray pedleri yardımıyla darbe kuvvetlerinin azaltılması üzerine çalışmıştır. Wu ve Thompson (2001), birden fazla tekerin varlığında ve farklı ray pedleri kullanımında hatta oluşan gürültüleri kıyaslamıştır. Leykauf ve Stahl (2004), elastik pedlerin hat üzerindeki etkilerini ortaya koyan bir çalışma gerçekleştirmiştir. Kaewunruen ve Remennikov (2006), ray pedi parametreleri ile travers titreşim karakteristiği arasındaki bağıntıyı incelemiştir. Clark ve diğerleri (1982), ondülasyonların, hat işletimi sırasındaki dinamik etkilerini ortaya koymuştur.

Teker/ray temas kuvvetleri: Yumuşak ray pedleri teker/ray temasının tahrip edici etkisini azaltır. Song ve diğerleri (2020), yaptıkları nümerik analizde ray pedinin teker/ray temas kuvvetlerini etkileyen en önemli parametre olduğu sonucuna ulaşt1lar [8]. Hiensch ve diğerleri (2002), Hollanda'da yaptıkları saha deneylerinde sert ray pedlerini yumuşak ray pedleriyle değiştirerek teker/ray etkileşiminin azaldığını gözlemlediler [18]. Bu durum, ray profili bozukluklarının gelişim hızını azaltmaktadır. Yüksek esneme direncine sahip ray pedi ise hatta antirezonans etkisine neden olur. Antirezonans durumunda hat, teker/ray etkileşimine karş1 oldukça sert ve dirençli davranır. Bu nedenle tüm parametreler aynı bile olsa, ortaya çıkan temas kuvveti daha fazladır [19]. Khajehdezfuly (2019), balastsız bir hatta çeşitli tren hızları için farklı sertlikteki pedlerin dinamik darbe kuvvetleri üzerindeki etkisini Şekil 3'teki gibi gözlemlemiştir [20]. Bu çalışmada çok yumuşaktan çok serte doğru ray pedi esneme dirençleri sırasıyla 20, 50, 80, 150, 300 ve $500 \mathrm{kN} / \mathrm{mm}$ 'dir.

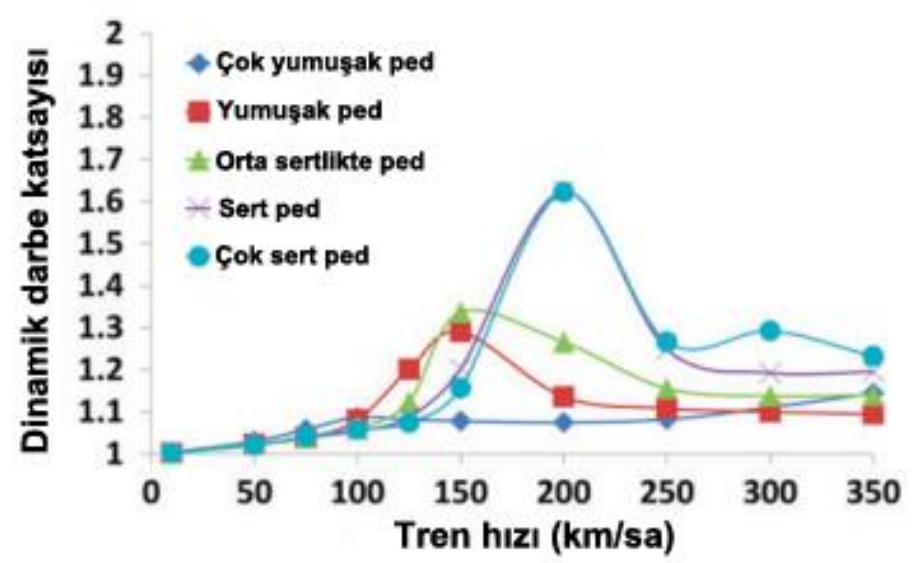

Şekil 3. Balastsız bir hatta farklı pedler için tren hızına bağlı olarak değişen dinamik darbe katsayısı [20]

Hat esneme direnci değişimleri: Esneme direnci farklı olan bölgeler arası geçişte etkiyen dinamik darbe kuvvetleri nedeniyle hat katmanlarındaki gerilmeler artar. Düşük esneme dirençli ray pedleriyle esneme direnci değişimlerinin etkisi önemli ölçüde azaltılabilir. 
Ray ondülasyonları: Ray ondülasyonları, ray yüzeyinde periyodik biçimde meydana gelen dalgalı aşınmalardır. Hat servis ömrü ve bakım maliyetleri göz önünde bulundurulduğunda kötü durumdaki bir hattın servis ömrü ahşap ve çelik traversli hatlarda $20 \%$ ve beton traversli hatlarda $30 \%$ azalmaktadır [4]. Bunun yanı sıra gürültüye neden olur, yolcu konforunu ve işletme güvenliğini azaltır ve ilerleyen durumlarda devrilmeye dahi yol açabilir. Ondülasyonların ana nedeni tam olarak bilinmese de, birkaç farklı mekanizmanın farklı şekillerde bir araya gelmesiyle meydana geldiği yönünde bir genel görüş hakimdir. Ondülasyonları etkileyen parametreler üzerinde çeşitli çalışmalar yapılmıştır [21].

Knothe ve Ripke (1989), ray pedinde malzeme özellikleri, kurulum, üretim toleransları, eskime veya iklim faktörleri nedeniyle meydana gelen esneme direnci artışının ondülasyonları arttırdığını tespit etmiştir [22]. Diana ve diğerleri (1998) Milan Metrosu'ndan elde ettikleri deneysel verilerle yaptıkları çalışmada ray pedi esneme direncindeki azalmanın, aşınmayı ve ondülasyon dalga boyunu azalttığını gözlemlediler [23]. Ilias (1999), $60 \mathrm{kN} / \mathrm{mm}$ ile $500 \mathrm{kN} / \mathrm{mm}$ arasındaki esneme direncine sahip ray pedleri için salınımlı kuvvet altındaki düşey ray sehimlerini inceledi [24]. Yüksek esneme dirençli ray pedi kullanımında, anti-rezonans halinin daha belirgin olduğunu ve travers üzerindeki ray pedinin dinamik vibrasyon önleyici nitelikte davrandığını gözlemledi. Bu durumda hat daha sert davrandığı için daha yüksek temas kuvvetleri meydana gelir ve ondülasyon gelişimi hızlanır.

Egana ve diğerleri (2006), ray pedi esneme direnci ile salınımlı kuvvet altındaki sehimi incelediklerinde yumuşak ray pedlerinin iki maksimum arasındaki anti-rezonansı önlediğini gördüler [25]. Birinci maksimum, hattın birinci maksimum düşey tepkisi ve ikinci maksimum ise bu tepki sonucundaki anti-rezonans ile ilgilidir. Bu nedenle inceledikleri hatta iki önemli ray ondülasyonu meydana gelmektedir. Yapılan çalışma, iki önemli ray ondülasyonundan bir tanesinin, yani anti-rezonans ile ilgili olan frekans aralığındaki maksimumun, ray pedi esneme direncinin azaltılmasıyla yok edilebileceğini göstermiştir. Uzun dalga boylu ondülasyon önemli ölçüde azaltılmış, kısa dalga boylu ondülasyon ise ortadan kaldırılmıştır. Şekil 4 'te farklı ray pedi esneme dirençlerinde ortaya çıkan anti-rezonans durumları gösterilmiştir.

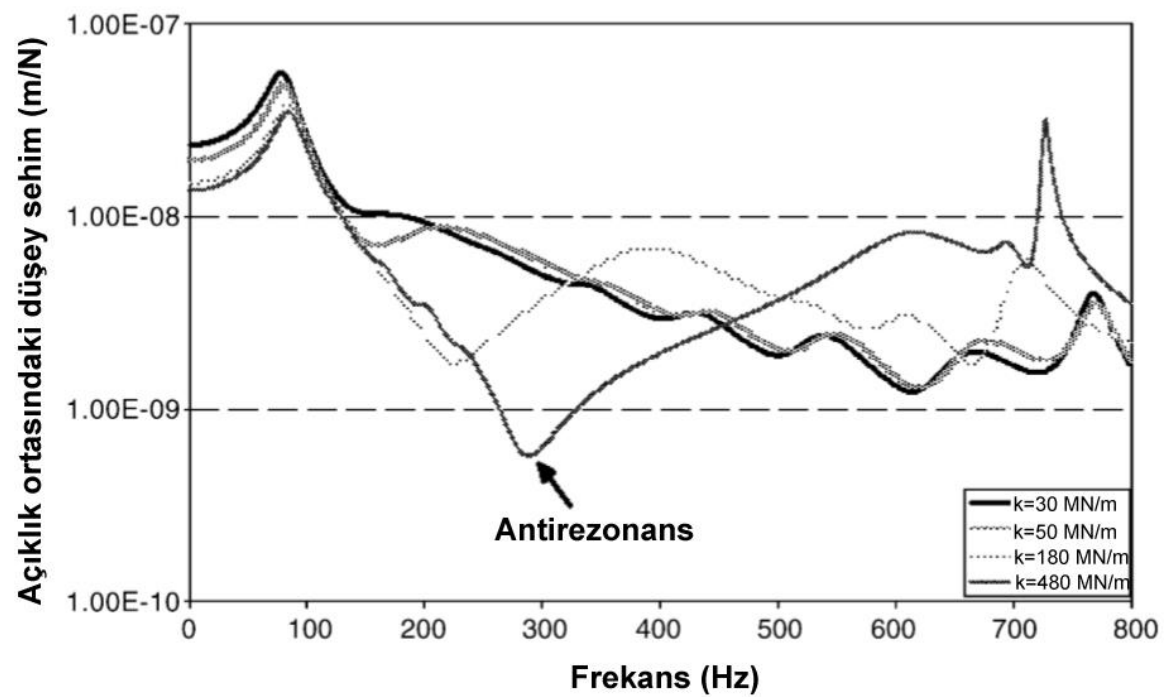

Şekil 4. Farklı ray pedi esneme dirençlerinde frekans ile açıklık ortasındaki düşey sehimin değişimi [25]

Grassie ve Elkins (1998), inceledikleri hatta $30 \mathrm{kN} / \mathrm{mm}$ 'den düşük esneme direncine sahip ray pedlerinin ondülasyon dalgasını engelleyeceğini tahmin etmişlerdir [26]. Egana ve diğerlerinin (2006) çalışması bu sonucu doğrulamış ve hatta kendi inceledikleri durumda $60 \mathrm{kN} / \mathrm{mm}$ esneme direncinin, dalgayı önlemek için yeterli olacağını göstermişlerdir [25]. 
Ray sehimleri: Genel hat davranışından bilindiği üzere, esneme direnci düşük ray pedi, eşdeğer hat esneme direncini azaltarak ray sehimlerinin artmasina neden olur. Khajehdezfuly'nin (2019) balastsız bir hat üzerindeki çalışmasından farklı sertlikteki pedler için elde edilen ray sehimleri Şekil 5'teki gibidir [20].

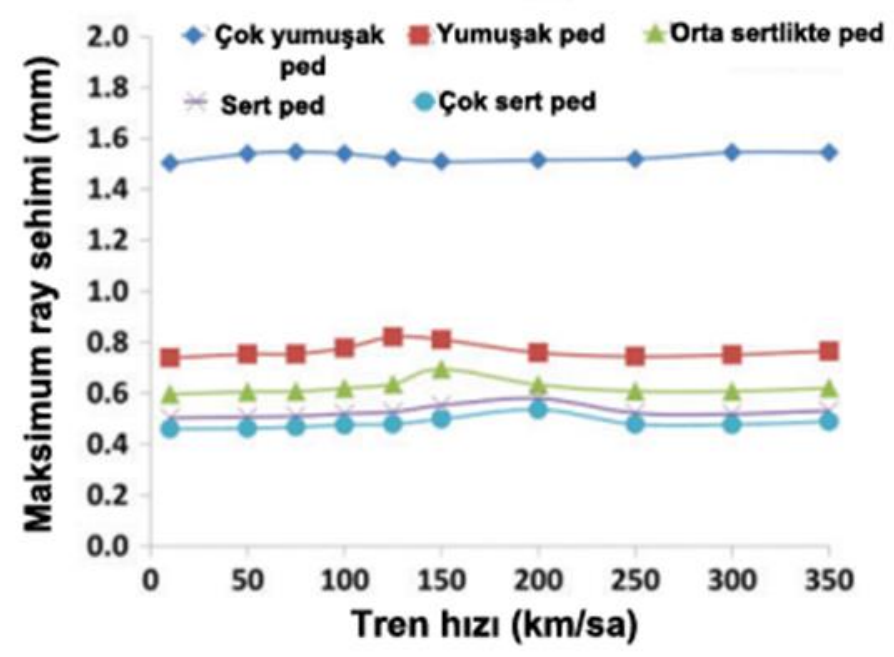

Şekil 5. Farklı tren hızları için çeşitli pedlerin kullanımında oluşan ray sehimleri [20]

Ray hareketleri: Esneme direnci düşük ray pedi kullanımı, rayı traversten izole ederek daha fazla ray hareketine neden olur. Bu da ray bağlantı elemanlarının servis ömrünü azaltır.

Alt katmanlara aktarılan gerilmeler: Ray pedinin esneme direnci azaldıkça alt katmanlara aktarılan gerilmeler daha eşit bir şekilde dağıtılır. Giannakos (2010) $250 \mathrm{kN} / \mathrm{mm}$ 'lik sert ray pedlerini $40 \mathrm{kN} / \mathrm{mm}$ 'lik yumuşak pedler ile değiştirdiğinde traverse aktarılan gerilmelerin $20 \%$ 'ye kadar azaldığını gözlemledi [27]. Çeşitli çalışmalarda, elastik ped kullanımının hatta aktarılan dinamik kuvvetlerin etkisini 50\% oranında azalttığı sonucuna ulaşılmıştır [28, 29].

Titreşim ve gürültü: Ray pedi esneme direnci, ray sönümlemesini ve ray ile traversin birlikteliğini etkiler. Esneme direnci çok düşük ray pedi kullanımında, traversler raydaki titreşimlerden büyük ölçüde izole edilir. Ancak titreşim ray boyunca serbestçe yayılabilir. Tam tersine, çok yüksek esneme dirençli ray pedi kullanımında ise ray ve travers birlikte hareket eder. Ray titreşimleri, ray-travers birlikteliği ve ped sönümlemesi tarafından kısıtlanır. Ancak bu durumda traversteki titreşim daha fazladır. Bu nedenle, ray pedinin esneme direnci arttıkça raydan kaynaklı gürültü azalır, traversten kaynaklı gürültü ise artar [27, 30]. Şekil 6'da ray pedi esneme direnci ile farklı elemanların neden olduğu gürültü arasındaki ilişki gösterilmiştir. 


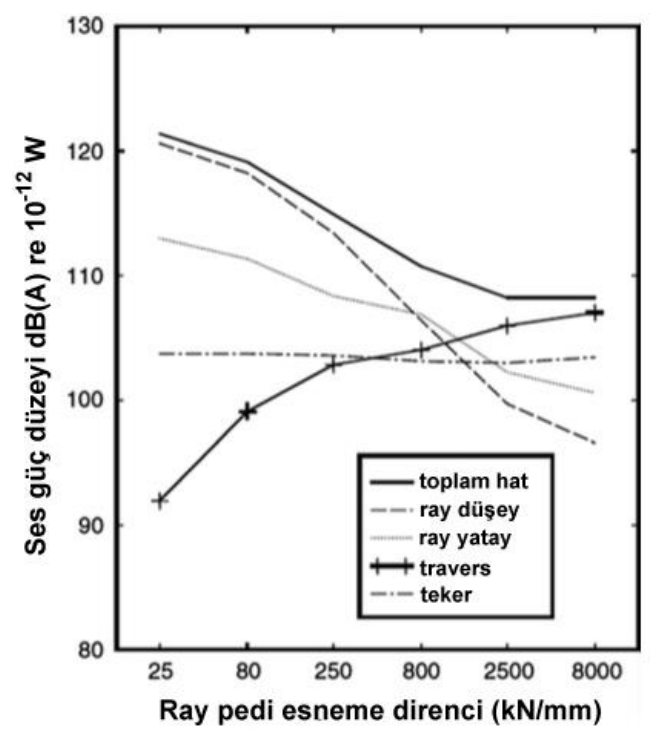

Şekil 6. Ray pedi esneme direnci ile hattaki gürültülerin değişimi [7]

Wu ve Thompson (2001), 68,8 kN/mm'lik yumuşak ray pedlerinin $270 \mathrm{kN} / \mathrm{mm}$ ve 1190 $\mathrm{kN} / \mathrm{mm}$ 'lik pedlere göre hattaki titreşimleri artırdığını ve $3 \mathrm{~dB}(\mathrm{~A})$ kadar teker/ray teması gürültüsü oluş̧urduğunu kaydetmiştir [31]. Ancak önceki çalışmaları onaylar şekilde, traversten kaynaklı gürültünün azaldığını belirtmiştir. Leykauf ve Stahl (2004), ray pedi esneme direncinin azaltılmasıyla balast tanelerindeki titreşimlerin azaldığını göstermiştir [32].

Travers hasarları: Traverslerin titreşimi, ön germeli beton traversler üzerinde oluşan çatlakların en önemli nedenlerinden biridir ve bu çatlaklar yüksek bakım maliyetleri gerektirir. Traversbalast etkileşimine ek olarak ray pedleri de traversin serbest titreşim karakterini etkiler [33]. Travers hasarı en çok rezonans frekanslarında meydana gelir. Ilias (1999), ray pedi esneme direnci arttıkça hat genel rezonansının da arttığı sonucuna ulaşmıştır [24].

Clark ve diğerlerinin (1982) yaptığı çalışmada, ray ondülasyonlarının yol açtığı titreşimlerin traverslere zarar verdiği ortaya konmuştur [34]. Tekerin ray ondülsayonları üzerinden geçişinde ortaya çıkan frekans, $60 \mathrm{~mm}$ dalga boylu ondülasyonda ve $45 \mathrm{~m} / \mathrm{s}$ tren hızında $750 \mathrm{~Hz}$ kadardır [34]. Esveld'e göre (2001) normal tren işletmesi sırasında ortaya çıkan dinamik kuvvetler, yaylanır kütle (sprung mass) için $0-20 \mathrm{~Hz}$ arasında ve yaylarla desteklenmeyen kütle (unsprung mass) için 20-125 Hz arasındadır [35]. Öte yandan, kötü ray kaynağı, ray ondülasyonları ve teker düzlükleri, tren hızına bağlı olarak $2000 \mathrm{~Hz}$ 'ye varan frekanslarda dinamik kuvvet oluşumuna neden olabilir. Bu da travers üzerinde olumsuz sonuçlar doğurur.

Esneme direnci düşük ray pedi, teker/ray etkileşiminden kaynaklanan titreşimleri ve dolayısıyla dinamik teker kuvvetinin neden olduğu tahribatı azaltır ve traversi çatlamaya karşı korur. Clark ve diğerleri (1982), trenin ray ondülasyonları üzerinden geçişinde travers hasarını önlemek için üç yöntem sunmuştur [34]. Bunlardan bir tanesi, yumuşak ray pedi kullanarak traversi raydaki uyarılardan izole etmektir. Ancak bu durumda rayların yanal hareketi, limit değeri aşabilir. İkinci yöntem, ray pedi veya balast tabakasının sönümlemesini artırarak hattaki pik rezonansları azaltmaktır. Bu da yüksek sönümlemeli ray pedi materyali geliştirilmesi veya balast tabakası kalınlığının artırılması ve balast temizliğinin muhafaza edilmesi ile sağlanabilir. Üçüncü yöntem ise travers rezonansı doğal frekansı ile tren hızından kaynaklı frekansın eşit olmasını önleyecek şekilde hat parametrelerini düzenlemektir. 1982 yılında Nottingham-Melton hattında yapılan bir deneysel çalışmada, rezonansın meydana geldiği iki pik frekans $220 \mathrm{~Hz}$ ve $630 \mathrm{~Hz}$ olarak tespit edilmiştir. Her iki durumda da pik değerlerin daha yüksek bir frekansa taşınabilmesi için yüksek esneme dirençli ray pedi kullanımı önerilmiştir [34]. 


\subsection{Travers altı pedler (USP) ve hat üzerindeki etkileri}

Travers altı pedler, hattın düşey elastisitesini artırmak ve ray ve traversler aracılığıyla balast, alt balast ve zemine aktarılan kuvvetleri en düzgün şekilde yaymak amacıyla travers tabanına yerleştirilen elastik pedlerdir. Hat bileşenlerinin servis ömrünü artırmak ve titreşimleri azaltmak için 1980'lerden beri kullanılmaktadır. Özellikle hat geometrik kalitesini artırmak amaciyla makas bölgelerinde kullanımı yaygındır. Travers altı pedler genellikle 2 veya 3 katmandan oluşur: Traverse yerleştirilen sönümleme özelliğine sahip gözenekli katman, elastik yay katmanı ve opsiyonel olarak kullanılan koruyucu tabaka. Travers altı pedi kalınlığı, $10 \mathrm{~mm}$ ile $20 \mathrm{~mm}$ arasında değişir ve genellikle $1 \mathrm{~m}$ uzunluktadır. Şekil 7(a)'da ped katmanları ve Şekil 7(b)'de saha uygulaması gösterilmiştir.

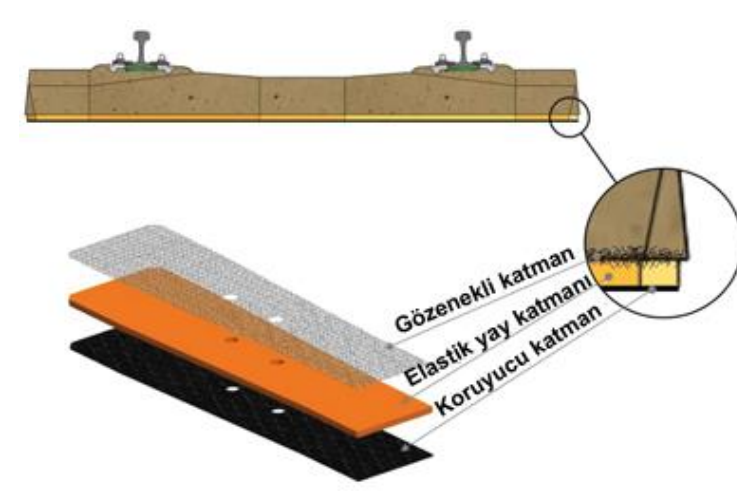

a)

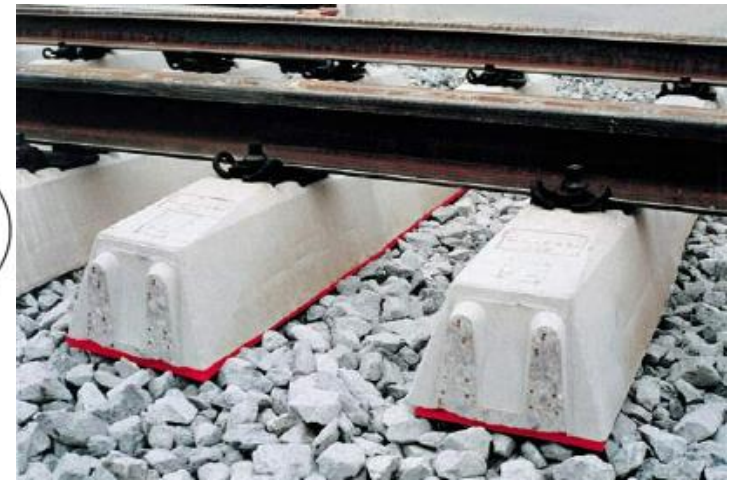

b)

Şekil 7. a) Travers altı ped katmanları [36] b) Saha uygulaması [37]

$\mathrm{Bu}$ pedler genellikle poliüretan elastomerler, kauçuk ve EVA (ethylene vinyl acetate) malzemelerinden üretilir. Ray pedlerinin aksine travers altı pedleri sınıflandırmak için belirli bir standart yoktur. Ancak Witt (2008) çalışmasında pedleri esneme direncine göre üç kategoride sınıflandırmıştır: Yumuşak (50 kN/mm), orta $(400 \mathrm{kN} / \mathrm{mm})$ ve sert $(3000 \mathrm{kN} / \mathrm{mm})$ [38]. Pedlerin esnekliğini derecelendirmek için esneme direnci yerine " $\mathrm{C}$ " $\left(\mathrm{N} / \mathrm{mm}^{3}\right)$ ile temsil edilen statik yatak modülü de kullanılır. Travers altı pedi kullanımının hat bileşenleri üzerindeki önemli etkileri şu iki madde ile açıklanabilir [16]:

- Normalde 3-4\% oranında olan balast tabakası ve travers arasındaki temas alanını 36\%'ya kadar artırarak traversten alt katmanlara aktarılan gerilmeleri azaltır. Böylece balast, alt balast ve zemin taneciklerinin yıpranmasinı azaltır [38-40].

- Yüksek esneme dirençli pedler ray ve traverslerdeki titreşimi azaltarak buradaki olası hasarları önler. Düşük esneme dirençli pedler ise balast tabakasındaki titreşimleri azaltarak taneciklerdeki yıpranmayı önler.

\subsection{Travers altı pedi esneme direncinin hat üzerindeki etkileri}

Travers altı pedinin esneme direnci hattın dinamik performansı üzerinde oldukça etkilidir. Pedin yumuşak veya sert olmasının her bir katman üzerinde farklı etkileri vardır. Farklı durumlar açısından tercih edilmesi gereken ped türleri Tablo 3'te verilmiştir. Devamında ise bu etkiler daha ayrıntılı olarak açıklanmıştır. 
Tablo 3. Sert ve yumuşak travers altı pedi kullanımının karşılaştırılması [1]

\begin{tabular}{lcc}
\hline \multicolumn{1}{c}{ Uygulama } & Sert ped & Yumuşak ped \\
\hline Hat esneme direnci değişimlerinin azaltılması & $\checkmark$ & $\checkmark$ (daha çok) \\
Ray ondülasyon gelişiminin azaltılması & $\checkmark$ & $\checkmark$ \\
Ray sehimlerinin azaltılması & $\checkmark$ & $\checkmark$ \\
Ray ve travers hareketinin engellenmesi & $\checkmark$ & \\
Gerilmelerin dağıtılması, balast oturmasının azaltılması & & $\checkmark$ \\
Ray ve traversteki titreşim ve gürültünün azaltılması & $\checkmark$ & \\
Balast tabakasındaki titreşim ve gürültünün azaltılması & & \\
\hline
\end{tabular}

Schilder (2006), balastlı hatlarda elastik ped kullanım uygulamalarını incelen bir çalışma yapmıştır. Müller-Boruttau ve diğerlerinin (2001) çalışmasında, travers altı pedlerin esneme direnci ile ray ve travers hareketleri arasındaki ilişki gözlemlenmiştir. Johansson ve diğerleri (2008), oluşturdukları model ile travers altı pedlerin dinamik hat-teker etkileşimine etkisini incelemiştir. Witt (2008) de oluşturduğu sonlu elemanlar modeli ile travers altı pedlerin tekertemas kuvvetleri ve balast temas kuvvetleri üzerindeki etkisini incelemiştir. López-Pita (2006), çalışmasında travers altı pedlerin balast tabakasındaki gerilmeler, titreşimler ve bunun sonucu olarak balast yıpranmaları üzerindeki etkilerine yer vermiştir. Schneider ve diğerleri (2011), yaptıkları arazi deneyi ile travers altı pedlerin hat kalitesi ve hat dinamiği ile ilişkisini gözlemlemiştir. Krüger (2007), yaptığı teorik incelemede travers altı ped kullanımının balast ve alt temel katmanlarına aktarılan gerilmeler üzerindeki etkisini ortaya koymuştur. Navaratnarajah ve diğerleri (2018), deneysel ve nümerik yöntemler ile travers altı ped ile balast davranış1 arasındaki ilişkiyi araştırmışlardır. Stahl (2004), Almanya'daki arazi deneylerine dayanarak travers altı ped elastikiyet değerinin değişimiyle balastlı hatlarda ortaya çıkan avantaj ve dezavantajları ortaya koymuştur. Jenkins ve diğerleri (1974), hat ve araç parametreleri ile dinamik teker kuvveti arasındaki ilişkiyi incelemiş, travers altı pedin etkilerine de yer vermiştir. Lakuši ve diğerleri (2010), travers altı ped kullanıldığı ve kullanılmadığ 1 durumlarda hatta oluşan titreşim şiddetlerini karşılaştırmıştır.

Hat esneme direnci değişimleri: Travers altı pedler, hat boyunca esneme direnci değişimi nedeniyle gerçekleşen temas kuvvetindeki dalgalanmaları azaltır. Esneme direnci düşük olan pedler bu açıdan daha iyi performans göstermektedir.

Ray ondülasyonları: Schilder (2006) yumuşak ped kullanımıyla küçük yarıçaplı kurplarda ray ondülasyonlarının azaltılabileceğini göstermiştir [41]. $\mathrm{R}=265$ m'lik bir kurpta $0,20-0,30 \mathrm{~N} / \mathrm{mm}^{3}$ yatay modülüne sahip travers altı pedler ile 25 GMT yükten sonra ray dalgalanmalarının 50\%'ye kadar azaldığı gözlemlenmiştir.

Ray sehimleri: Hannover-Gottingen hattında $30-70 \mathrm{kN} / \mathrm{mm}$ arası değişen travers altı pedler kullanıldığında pedlerin, hat geometrisinin bozulma hızını azalttı̆̆ı görüldü. Kalıcı ray sehimlerindeki artış oranı, ped kullanılmayan duruma göre 25-30\% oranında azaldı [12]. Avusturya'daki hatlarda yapılan çalışmada $0,20 \mathrm{~N} / \mathrm{mm}^{3}$ yatak modülüne sahip pedlerin kullanıldığı hat ile pedsiz hat arasında $1 \mathrm{~mm}$ 'den fazla kalıcı ray sehimi farkı gözlemlenmiştir [41].

Ray ve travers hareketi: Alman Demiryolları, $70-80 \mathrm{kN} / \mathrm{mm}$ 'lik travers altı pedlerin kullanıldığ çalışmada, esneme direncindeki azalmanın ray ve travers hareketlerinde 30-50\% oranında artışa neden olduğunu göstermiştir [42]. Ayrıca yüksek esneme dirençli pedler ray momentini de azaltır. 
Johansson ve diğerleri (2008), oluşturdukları model ile ray pedi, travers altı ped ve balast-alt temel tabakalarının esneme direncini hesaba katarak ray ve travers hareketlerini gözlemlendi [43]. Modelde, ray pedi için düşük (-), orta (0) ve yüksek (+) esneme dirençleri $63 \mathrm{kN} / \mathrm{mm}, 118 \mathrm{kN} / \mathrm{mm}$ ve $644 \mathrm{kN} / \mathrm{mm}$ olarak ele alındı. Travers altı pedi için ise bu değerler sırasıyla $35 \mathrm{kN} / \mathrm{mm}, 70$ $\mathrm{kN} / \mathrm{mm}$ ve $105 \mathrm{kN} / \mathrm{mm}$ 'dir. Balast ve alt temelin düşük (-) ve yüksek (+) esneme dirençleri ise sırasıyla $40 \mathrm{kN} / \mathrm{mm}$ ve $100 \mathrm{kN} / \mathrm{mm}$ 'dir. Şekil 8 ve 9, travers altı pedin esneme direncine bağl1 olarak düşey ray yer değiştirmelerini ve düşey travers ivmelenmelerini göstermektedir.

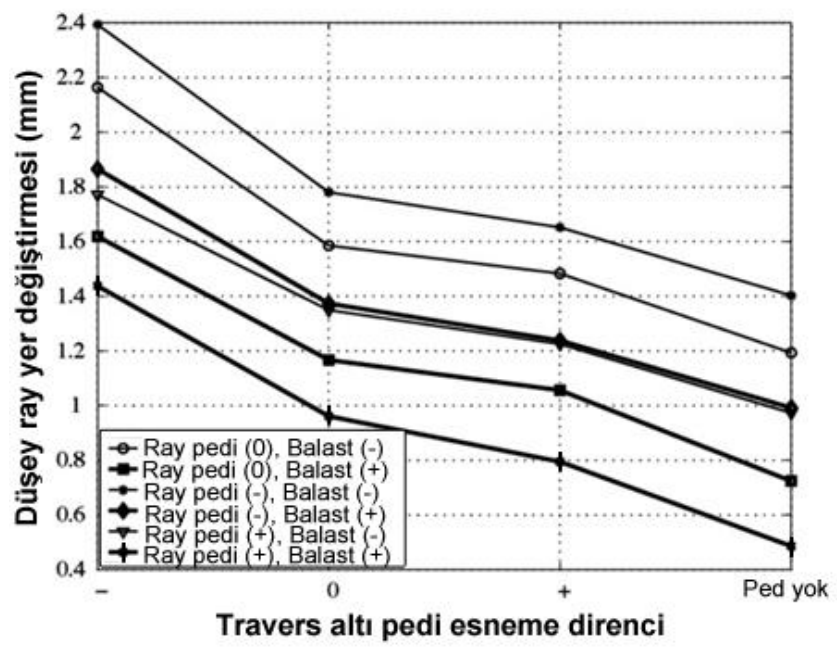

Şekil 8. Hat bileşenlerinin esneme dirençlerine bağlı olarak düşey ray yer değiştirmesi [43]

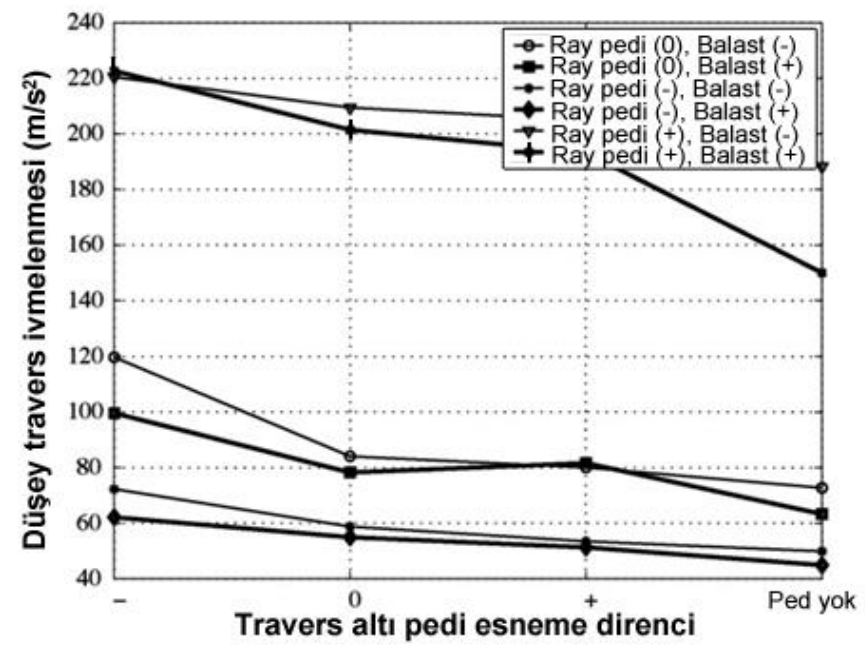

Şekil 9. Hat bileşenlerinin esneme dirençlerine bağlı olarak düşey travers ivmelenmesi [43]

Gerilme nedeniyle balast oturması: Travers altı ped kullanıldığında balast tabakası ile temas, kullanılmadığı durumdakine göre yaklaşık 10 kat daha fazladır. Temas alanının artması, balast tabakasındaki basıncı ve dolayısıyla aşınmayı azaltır [38, 43]. Balast oturmasının temel nedeni balast tanelerinin yıpranmasıdır. Travers altı pedlerin kullanımıyla tanecik hasarlarının ve balast sıvılaşması probleminin görülme riski de azalmaktadır. López-Pita'nın (2006) yaptığı çalışmada travers altı ped kullanımının tanecikli katmanlardaki gerilmeleri azalttığı ortaya konmuştur [12]. Alman Demiryolları tarafından yapılan çalışmada da 70-80 kN/mm esneme dirençli pedlerin balast tabakasındaki gerilmeleri $35 \%$ oranında azalttığı görülmüştür [42].

Pedin esneme direnci azaldıkça, yük dağıtma kapasitesi artar. Bu nedenle balast gerilmeleri dikkate alındığında yumuşak ped kullanımı tercih edilir. $0,30 \mathrm{~N} / \mathrm{mm}^{3}$ yatak modülüne sahip 
pedlerin hattın eşdeğer esneme direncini düşürdügü ve travers ve balast tabakasındaki gerilmeleri azalttığı görülmüştür $[38,44]$. Krüger $(2007), 0,05 \mathrm{~N} / \mathrm{mm}^{3}$ yatak modülüne sahip travers alt1 pedlerin, balast ve alt temele aktarılan kuvveti 140\%'ı aşkın oranda azalttığını göstermiştir [45]. Navaratnarajah ve diğerleri (2018), oluşturdukları simülasyon modeli ile 35 ton yük altında ve 15 $\mathrm{Hz}$ frekansta travers altı ped kullanılan ve kullanılmayan durumları kiyaslayarak balast tabakasındaki düşey gerilmeleri Şekil 10'daki gibi bulmuşlardır [46].
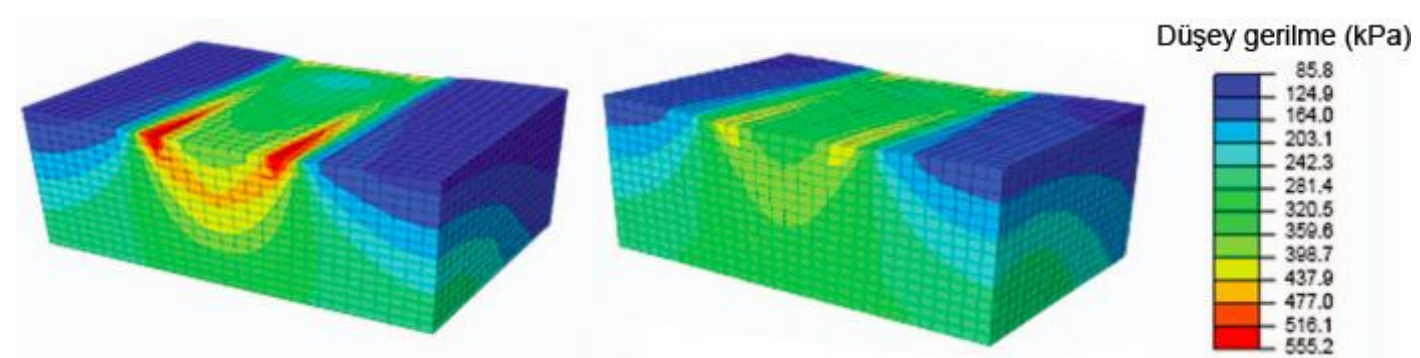

Şekil 10. Travers altı ped kullanılmayan (solda) ve kullanılan (sağda) durumlarda balast tabakası kesitindeki düşey gerilmeler [46]

Titreşimler: Travers altı ped kullanımının titreşim açısından hattın farklı katmanları üzerinde farklı etkileri vardır. Pedin esneme direnci azaldıkça travers ve raydaki titreşimler artar. Diğer yandan, pedin esneme direncinin artmasıyla da balast tabakasındaki titreşimler artar.

Tokaido-Shinkasen hattında kullanılan $68 \mathrm{kN} / \mathrm{mm}$ 'lik travers altı pedlerin balast tabakasındaki titreşimleri $22 \%$ oranında azalttı̆g 1 gözlemlendi [12]. Stahl (2004), $63 \mathrm{~Hz}$ frekansta ve ped kullanımıyla travers tarafindan alt katmanlara aktarılan titreşimlerin 45\%'e kadar azaldığ sonucuna ulaştı [47]. Ayrıca, travers altı pedi kullanılan ve sert bir ray pedine sahip bir hat ile travers altı pedi bulunmayan ama yumuşak bir ray pedine sahip bir hattın benzer mekanik performans gösterdiğini tespit etti. Jenkins ve diğerleri (1974), $3 \mathrm{~cm}$ kalınlığındaki travers altı pedler kullandığında hat tarafından iletilen toplam titreşim 30\% oranında azalmıştır [48].

Gürültü: Avrupa'da travers altı pedler kullanılarak yapılan çalışmalarda tüm pedler için 16-31,50 $\mathrm{Hz}$ aralığında rezonans frekansları gözlemlendi. Çalışmada bu frekans aralığı yüksek gürültüye neden olmuştur. Ancak $40 \mathrm{~Hz}$ üstü frekanslarda gürültüde önemli bir azalma meydana gelmiştir. $\mathrm{Bu}$ frekanslardaki gürültü 8-15 dB aralığındadır [49]. Hırvatistan'daki deneysel çalışmada da pedler sayesinde özellikle $5-250 \mathrm{~Hz}$ aralığında gürültü̈de azalma kaydedilmiştir [36].

\section{Sonuç}

Bir trenin demiryolu hattı üzerinden geçişinde aynı anda birçok farklı olay gerçekleşir. Teker yüklerinin dağıtımı, farklı hat katmanlarında meydana gelen titreşim ve gürültü, ray ve travers hareketleri gibi durumlar hat geometrik kalitesindeki değişimler ve dolayısıyla hattın performansı üzerinde belirleyicidir. Yapılan çalışmada elastik pedlerin esneme direncinin her bir katmanda farklı etkilere sebep olduğu görülmüştür. Ray pedleri için şu sonuçlara ulaşılmıştır:

1. Yumuşak ray pedi kullanımıyla teker/ray temas kuvvetleri ve ray sehimleri azaltılabilir. Hattın servis ömrünü azaltan ray ondülasyonları engellenebilir. Raydan traverse aktarılan gerilmeler 50\%'ye kadar azaltılabilir. Ayrıca travers ve balast tabakasındaki titreşimler azaltılabilir. Bu nedenle traversteki çatlak oluşumları gecikir.

2. Sert ray pedi kullanıldığında ray sehimleri daha azdır. Travers ve ray birlikte hareket eder. $\mathrm{Bu}$ nedenle hem ray hareketleri engellenir hem de raydaki ve hattaki toplam titreşim daha azdir.

Travers altı pedler için ise şu sonuçlar elde edilmiştir: 
1. Yumuşak travers altı pedler, hattaki esneme direnci değişimlerini daha iyi absorbe eder. Dar kurplardaki ray ondülasyonları 50\%'ye kadar azaltılabilir. Alt tabakalara aktarılan gerilmeler 140\%'1 geçkin bir oranda azaltabilir. Balast tabakasındaki titreşimler de daha azdir.

2. Sert travers altı pedlerde ray sehimi, ray ve traverslerin hareket kabiliyeti, ray momentleri ve ray ve traversteki titreşimler daha azdır.

Mevcut bir hattın esneme direncinde yapılacak değişimler, farklı katmanlardaki gerilme, moment, titreşim ve yer değiştirme kriterleri açısından olumsuz sonuçlara da neden olabilmektedir. Maksimum hat performansının sağlanabilmesi için elastik pedlerin esneme direncinin yukarıda yer alan etkileri göz önünde bulundurulmalıdır. Yeni inşa edilecek bir demiryolunun tasarımında, elastik pedler için tüm bu kriterlerin güvenlik koşulunu sağlayacak optimum bir esneme direnci seçilmelidir. Yenileme çalışmalarında, hattaki mevcut problemlerin çözümü amaç edinilerek elastik pedler farklı bir esneme direncine sahip pedler ile değiştirilebilir. Ancak yenileme işleminin olumsuz yönleri de ele alınmalı ve esneme direncindeki değişimin etkileri hattın bütünü için değerlendirilmelidir.

$\mathrm{Bu}$ çalışmada elastik pedlerin esneme direncinin değişimiyle hat performansını etkileyen parametrelerin değişimleri ortaya konmuştur. Hatların karakteristiğine göre elastik pedlerin dinamik davranışı değişmektedir. Bu nedenle her hat için ihtiyaç duyulan elastik ped esneme direnci değeri farklıdır. Gelecek çalışmalarda, farklı hatlardan alınan veriler analiz edilerek maksimum hat performansını sağlayan optimum ray pedi esneme direnci değerleri ortaya konmalıdır. Farklı koşullara sahip hatlar arasındaki optimum ped esneme direnci değerinin değişim miktarı ve bu değişimi etkileyen parametreler ile optimum ped esneme direnci arasındaki bağıntı incelenmelidir.

\section{Kaynakça}

[1] M. Sol-Sánchez, F. Moreno-Navarro, and M. C. Rubio-Gámez, "The use of elastic elements in railway tracks: A state of the art review," Constr and Build Mater, vol. 75, pp. 293-305, 2015.

[2] J. Nielsen, A. Johansson, and T. Vernersson, "Train-track interaction and mechanisms of irregular wear on wheel and rail surfaces," Vehicle Syst Dyn, vol. 40, no. 1-3, pp. 3-54, 2003.

[3] P. F. Teixeira, "Contribución a la reducción de los costes de mantenimiento de vías de alta velocidad mediante la optimización de su rigidez vertical," Ph.D. dissertation, E.T.S. Ingenieros de Caminos, Canales y Puertos, 2003.

[4] V. Arlı, "Demiryolu Mühendisliği (genişletilmiş 2. baskı)," İstanbul: Birsen Yayınevi, 2015.

[5] E. T. Selig, J. M. Waters, "Track geotechnology and substructure management," London: Thomas Telford; 1994.

[6] H. Xia, N. Zhang, and W. W. Guo, "Analysis of resonance mechanism and conditions of train-bridge system,” J Sound Vib, vol. 297, no. 3-5, pp. 810-822, 2006.

[7] D. J. Thompson, C. J. C. Jones, "Noise and vibration from railway vehicles," Handbook of Railway Vehicle Dynamics, New York, USA. CRC Press, Taylor \& Francis, 2006, pp. 279-325.

[8] X. Song, Y. Qian, K. Wang, and P. Liu, "Effect of rail pad stiffness on vehicle-track dynamic interaction excited by rail corrugation in metro," Transp Res Record, vol. 2674, no. 6, pp. 225-243, 2020.

[9] Gürmak Demiryolu, "W21 Ray Bağlant1 Sistemi" [Online]. Available: https://www.gurmakdemiryolu.com.tr/tr/urunlerimiz/w21-ray-baglanti-sistemi/. [Accessed July 7, 2020].

[10] Indiamart, "Grooved rubber sole plates rail pad" [Online]. Available: https://www.indiamart.com/proddetail/grooved-rubber-sole-plates-rail-pad-20756032791.html. [Accessed July 7, 2020].

[11]EN 13481-2. Railway applications-track-performance requirements for fastening systems. Fastening systems for concrete sleepers.

[12] A. López-Pita, Ed., Infraestructuras ferroviarias. Barselona, İspanya: Edicions UPC, 2006. 
[13] A. Gomes Correia, J. Cunha, "Analysis of nonlinear soil modeling in the subgrade and rail track response under HST," Transport Geotech, vol. 1, no. 4, pp. 147-156, 2014.

[14] N. Hasan, "Rail pad stiffness and classification system," J Transp Eng, Part A: Systems, vol. 145, no. 5, $04019012,2019$.

[15] M. Sol-Sánchez, F. Moreno-Navarro, and M. C. Rubio-Gámez, "The use of deconstructed tire rail pads in railroad tracks: Impact of pad thickness," Mater Design, vol. 58, pp. 198-203, 2014.

[16]E. Balc1, N. Ö. Bezgin, "Hat esneme direncinin hat performansı üzerindeki etkileri," Demiryolu Mühendisliği, vol. 11, pp. 75-85, 2020.

[17] Setsobhonkul, S., Kaewunruen, S., \& Sussman, J. M. (2017). Lifecycle Assessments of Railway Bridge Transitions Exposed to Extreme Climate Events. Frontiers in Built Environment, 3. doi:10.3389/fbuil.2017.00035

[18] M. Hiensch, J. C. O. Nielsen, and E. Verheijen, "Rail corrugation in The Netherlands-measurements and simulations," Wear, vol. 253, pp. 140-149, 2002.

[19] Thompson, D., "Railway Noise and Vibration: Mechanisms, Modelling and Means of Control," Oxford, UK: Elsevier, 2009.

[20] A. Khajehdezfuly, "Effect of rail pad stiffness on the wheel/rail force intensity in a railway slab track with short-wave irregularity," P I Mech Eng F-J Rai, 095440971882541, 2019.

[21] Y. Sato, A. Matsumoto, and K. Knothe, "Review on rail corrugation studies," Wear, vol. 253, pp. 130139, 2002.

[22]K. Knothe, B. Ripke, "The effects of the parameters of wheelset, track and running conditions on the growth rate of rail corrugations," in Proceedings of the 11th IAVSD Symposium. Kingston, Ontario, CA, 1989, pp. 345-356

[23] G. Diana, F. Cheli, S. Bruni, and A. Collina, "Experimental and numerical investigation on subway short pitch corrugation," Vehicle Syst Dyn, vol. 28, pp. 234-245, 1998.

[24]H. Ilias, "The influence of railpad stiffness on wheelset/track interaction and corrugation growth," $J$ Sound Vib, vol. 227, pp. 935-948, 1999.

[25] J. I. Egana, J. Vinolas, and M. Seco, "Investigation of the influence of rail pad stiffness on rail corrugation on a transit system," Wear, vol. 261, no. 2, pp. 216-224, 2006.

[26] S. L. Grassie, J. A. Elkins, "Rail corrugation on north american transit systems," Vehicle Syst Dyn, vol. 28, pp. 5-17, 1998.

[27]K. Giannakos, "Influence of rail pad stiffness on track stressing, life-cycle and noise emission," in Proceeding of the second international conference on sustainable construction materials and technologies, Marche, Italy, 2010

[28] S. Kaewunruen, A. M. Remennikov, “An experimental evaluation of the attenuation effect of rail pad on flexural behaviour of railway concrete sleeper under severe impact loads," in Proceeding of the 2008 Australian structural engineering conference, Melbourne, Australia, 2008

[29] I. Carrascal, J. A. Casado, S. Diego, and J. A. Polanco, "Atenuación frente a impacto en sistemas de sujeción ferroviaria de alta velocidad,” J Anales Mecán Fract, vol. 28, no. 2, pp. 713-718, 2011.

[30]N. Vincent, P. Bouvet, D. J. Thompson, and P. E. Gautier, "Theoretical optimization of track components to reduce rolling noise," J Sound Vib, vol. 193, no. 1, pp. 161-171, 1996.

[31] T. X. Wu, D. J. Thompson, "The effects on railway rolling noise of wave reflections in the rail and support stiffening due to the presence of multiple wheels," Appl Acoust, vol. 62, pp. 1249-1266, 2001.

[32] G. Leykauf, W. Stahl, "Untersuchungen und Erfahrungen mit besohlten Schwellen," EI Der Eisenbahningenieur, vol. 55, no. 6, pp. 8-16, 2004.

[33] S. Kaewunruen, A. M. Remennikov, "Sensitivity analysis of free vibration characteristics of an in situ railway concrete sleeper to variations of rail pad parameters," J Sound Vib, vol. 298, no. 1-2, pp 453461, 2006.

[34] R. A. Clark, P. A. Dean, J. A. Elkins, and S. G. Newton, "An investigation into the dynamics effects of railway vehicles running on corrugated rails," J Mech Eng Sci, vol. 24, pp. 65-76, 1982.

[35]C. Esveld, "Modern Railway Track, second ed.," The Netherlands: MRT-Productions, 2001.

[36] S. Lakuši, M. Ahac, and I. Haladin, "Experimental investigation of railway track with under sleeper pad," in 10th Slovenian road and transportation congress, Ljubljana, Slovenia, 2010, pp. 20-22

[37] H. Loy, "Under Sleeper Pads: Improving Track Quality while Reducing Operational Costs," European Railway Review, vol. 4, pp. 46-51, 2008.

[38] S. Witt, "The influence of under sleeper pads on railway track Dynamics," Magister dissertation, Dept. Manage. Eng., Solid Mech. Div., Linköping Univ., Linköping, Sweden, 2008

[39]F. N. Müller-Boruttau, V. Rosenthal, and N. Breitsamter, "Innovative ballasted track: concrete sleepers with sole pads," WCRR. Cologne, Germany, 2001 
[40] A. Riessberger, "Ballast track for high speeds," Proceedings of Tracks for High-Speed Railways, Porto, Portugal, 2006, pp. 23-44

[41] R. Schilder, 2006. UIC Project no. I/05/U/440 USP-Under Sleeper Pads. Applications and Benefits of Elastic Elements in Ballasted Tracks UIC, Paris 17.

[42]F. Müller-Boruttau, U. Kleinert, "Betonschwellen mit Elastischer Sohle," ETR, vol. 50, no. H3, pp. 90-98, 2001.

[43] A. Johansson, J. C. O. Nielsen, R. Bolmsvik, and A. Karlström, "Under sleeper pads - influence on dynamic train-track interaction," Wear, vol. 265, pp. 1479-1687, 2008.

[44] P. Schneider, R. Bolmsvik, and J. C. O. Nielsen, "In situ performance of a ballasted railway track with under sleeper pads," P I Mech Eng F-J Rai, vol. 225, no. 3, pp. 299-309, 2011.

[45] M. Krüger, 2007. Theoretical Investigations/Calculations. Work Package Number 2a of UIC Project Under Sleeper Pads.

[46] S. K. Navaratnarajah, B. Indraratna, and T. N. Ngo, "Influence of Under Sleeper Pads on Ballast Behavior Under Cyclic Loading: Experimental and Numerical Studies," J Geotech Geoenviron, vol. 144, no. 9, 04018068, 2018.

[47] W. Stahl, "Improvement of ballasted tracks using sleeper pads - investigations and experiences in Germany," in Proceedings Seventh International Conference on the Bearing Capacity of Roads, Railways and Airfields, Trondheim, Norway, 2005

[48] J. Jenkins, S. Stephenson, G. Clayton, G. Morland, and D. L. Lyon, "Incidences des paramètres caracteristiques de la voie et des vehicules sur les efforts dynamics verticaux qui se développent entre rail et roue," Rail International, vol. 10, 1974.

[49] UIC (International Union of Railways) USP Report, Project no. I/05/U/440, 2009

\section{Özgeçmiş}

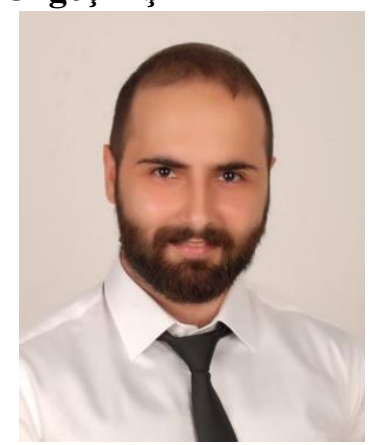

Beyanlar:

\section{Erdem BALCI}

1994 tarihinde Wuppertal, Almanya'da doğmuştur. Lisans eğitimini Karadeniz Teknik Üniversitesi'nde tamamlamıştır. İstanbul Üniversitesi-Cerrahpaşa İnşaat Mühendisliği ve Yıldız Teknik Üniversitesi Bilgisayar Mühendisliği bölümlerinden yüksek lisans derecesi elde etmiştir. Şu anda İstanbul Üniversitesi-Cerrahpaşa'da doktora eğitimine devam etmektedir. Ulaştırma anabilim dalında demiryolu mekaniği üzerine araştırmalarda bulunmaktadır.

E-Posta: erdembalci@outlook.com

Bu makalede bilimsel araştırma ve yayın etiğine uyulmuştur. 